\title{
Roma health: Do we know enough?
}

\author{
Jitse P. van Dijk ${ }^{1,2,3}$
}

Received: 13 March 2019/Revised: 20 March 2019/ Accepted: 27 April 2019/Published online: 10 May 2019

(C) Swiss School of Public Health (SSPH+) 2019

In general, we know that socioeconomic status (SES) is related to health outcomes: the lower the SES, the lower the health outcomes. For Roma, we also know that this low SES in terms of education or unemployment is associated with their low health outcomes. We also know that what is $<$ low $>$ among the non-Roma population differs quite a lot from $<$ low $>$ among the Roma population and that they are simply not comparable.

What we do not understand-where a knowledge gap does exist - is the causal mechanism behind all this; this is the million dollar question. In a scientific environment where quantitative research is the norm, we might perhaps have a look at what well-designed qualitative research can offer us regarding these mechanisms (Belak et al. 2018). Furthermore, knowledge gaps exists regarding the prevalence of communicable and non-communicable diseases among Roma and further, about the number of publications on both types of diseases.

To unveil causal mechanisms, it is necessary that scientists merge some links between computer files, where data of different origin are stored. Ethnicity is not included in many files, for several good reasons related to the Second World War. Scientists can walk one of two ways: either they convince their different national parliaments to change this or they make this link themselves in order to unveil the causal mechanisms behind health disparity. To give an example: as ethnicity is not included in, e.g. birth registers, linking these data with data from

Jitse P. van Dijk

j.p.van.dijk@umcg.nl

1 Department Community and Occupational Medicine, University Medical Center Groningen, University of Groningen, Ant. Deusinglaan 1, 9713 AV, Groningen, The Netherlands

2 Graduate School Kosice Institute for Society and Health, Kosice, Slovakia

3 Health of Vulnerable Groups, Olomouc University Society and Health Institute, Palacky University, Olomouc, Czech Republic the Census (where ethnicity is noted) is a very good choice.

Organizing health care might seem to be easy (Van Dijk 2008). Research institutes produce epidemiological data on health or health risk behaviour. However, the situation is not always that simple and is not simple for Roma health, too. Bachrach and Baratz (1962), who were interested in discovering why there was such an enormous degree of poverty in a society as prosperous as the USA, developed an analytical model which helped them to understand this situation (Bachrach and Baratz 1970). They modelled the policymaking process as a kind of pipeline containing four valves (Van Dijk 2008). Valve number one concerns community values, which permit or hinder an issue from coming onto the agenda at all. When the issue has reached this stage, it has to pass through the second valve. This consists of many kinds of procedures, committees and institutions that need to modify the issue to make it acceptable within the decision-making arena. The third valve is the decision-making process itself. The fourth valve shows the implementation process. All four valves can be open or closed. If one of the valves is closed, an attempt to change a certain policy cannot succeed. In sum, an issue has to pass through all four valves successfully before a new policy will be successful, with one closed valve being enough to derail the intended policy. Then, the issue will not be on the agenda for years (Van Dijk 2008).

Evidence should not be used as indicated in the preceding paragraph. We should keep in mind that all the valves in the model are operated by groups of people who are in favour of preserving the status quo and thus want to keep the valves closed, while other groups in favour of change want the valves to be opened and try to use their influence to achieve this. Only a coalition of groups is able to open the valves. These groups should share the same interests - at least for a short time - and should be prepared to cooperate throughout the process. Getting an issue such as Roma health onto the agenda is not enough, as the issue also has to pass through the next valves, to begin with the policy formulation valve with a law on this issue being 
drafted. Such a law must then pass the parliament, acting as the third valve, while the fourth valve refers to the implementation and monitoring of the law. In this example, Roma health experts occupy the position of those who want to make a change, while a part of society is most probably in favour of preserving the status quo-not change society in favour of Roma health. In different countries, groups in their attempt to influence the valves of the model look for different partners.

Those who are in favour of change should find coalition partners in order to be powerful enough to change society in such a way that Roma health improves-a restricted scientific approach will not be enough. However, it is questionable whether this is a task for the University.

\section{References}

Bachrach P, Baratz MS (1962) Two faces of power. Am Polit Sci Rev 56:947-952

Bachrach P, Baratz MS (1970) Power \& poverty: theory \& practice. Oxford University Press, New York

Belak A, Madarasova Geckova A, van Dijk JP, Reijneveld SA (2018) Why don't segregated Roma do more for their health? An explanatory framework from an ethnographic study in Slovakia. Int J Public Health 63(9):1123-1131

Van Dijk JP (2008) Public health facts-why don't they lead to healthy public policy? Int J Public Health 53:121-122. https:// doi.org/10.1007/s00038-008-0241-x

Publisher's Note Springer Nature remains neutral with regard to jurisdictional claims in published maps and institutional affiliations. 